\title{
Design and analysis for manipulator fixture applications
}

\author{
Ming-Chu Hsieh ${ }^{1, *}$ and Zhen-Hong Khong ${ }^{2}$ \\ ${ }^{1}$ Department of Mechanical Engineering, National Chin-Yi University of Technology, Taiwan \\ ${ }^{2}$ Department of Mechanical Engineering, National Chin-Yi University of Technology, Taiwan
}

\begin{abstract}
The manipulators arms are the most important components in automatic machinery and equipment. These arms must conform to product requirements and match important accessory devices such as clamping jaw so that the entire process operates properly. Therefore the most important issue is that the manipulator arm has only one clamping jaw, followed by other issues such as welding and related features. In this research the manipulator arm of automated machinery with attached equipment was optimized, and the design serves as an object of study for multifunctional applications. This research emphasizes on customized manipulator design to create products with distinguished styles and characteristics, and serve as a basis for an improvement on innovative design. Manipulator arms from different manufacturers with various head-disc size and screw-hole locations were investigated, and concept of human palm was incorporated in the design to create a mechanical fixture that can be fitted into the arm. Overall design including main body of the manipulator, pneumatic cylinder set, gear and connecting rod combination, planet gear set, and linkage rods and fixture. These components were combined to offer the functions of the manipulator. Commercial software package, SolidWorks, was used to construct the model for the manipulator arm, and CAE analysis was implemented to identify the stress on the structure and possible interferences of the mobile components. Stress analysis was also performed on the gear set under pneumatic loading to ensure that the gear mechanism has a sufficient strength. The results of this study showed that an arc shaped manipulator body is the most easily handled during installation and most effectively controlled during operation. The simple profiles of the manipulator also lower the space required for storage. The design of the gear set and integrated application of the shaft helps prevent loosening of gear and shaft during operation. In this study, a manipulator was designed with three different functions, each fixture is powered by an isolated pneumatic cylinder, and this mechanism can be manipulated to form $0^{\circ}$ to $180^{\circ}$ clamping action in accordance with requirements of the task. The methods and results of this study serve as a reference for machinery industry to achieve high quality product, and also as a basis for innovative design.
\end{abstract}

*Corresponding author: smj@ncut.edu.tw 


\section{Introduction}

With the progress of time, the uses of robots for various occasions with diverse applications are increasing in the market. Presently, the definition of a robot is very inclusive; i.e., an automation system combined with a machine structure is called a robot. The objective behind the development of robots is to simplify life, substitute humans in harsh work environments, or execute difficult actions. Firstly, the platform for robotic development is anthropomorphosis, i.e., a robot imitates the human vision of judging objects and the actions of human hand joints and fingers. Therefore, mechanical arms refer to automatic control equipment that imitates the functions of the human arm to complete various operations.

With the increase in the demand of manufacturers for automatic production, the development of the mechanical arm industry has accelerated. Generally, mechanical arms are substitutes for humans to execute dangerous, massive, and dull work. Currently, the applications of mechanical arms are automatic gripping jaw, welding, paint spraying, assembling, etc. The technologies related to the mechanical arm involve subjects of machinery, electronics, automatic control, artificial intelligence (AI), kinematics, biomechanics, sensor technology, information processing, bionics, neural network, material science, etc. Thus, the application of mechanical arms to the manufacturing industry is accompanied with cost reduction, various processing modules, and labor-saving performance, and is an important topic worthy of discussion.

The application of mechanical arms in high-tech automated production lines and in handling or assembling has been popularized, such as spraying, welding, and assembling the car body in the automobile industry. The geometric shapes and functions of mechanical arms in various fields are varied owing to different usage objectives and environments. Mechanical arms are automatic control equipment that completes various operations by imitating the functions of the human arm; they possess multi-joint connections, and can act and move linearly in plane and three-dimensional spaces. A mechanical arm is composed of a mechanical main body, controller, servo mechanism, and sensor, and its actions are set by the program input by a computer according to the operation demands.

The design of a low degree of freedom system enables robots to be lightweight and simple [1], and further assembles the system itself during the simulation and controller design. Additionally, it helps in going beyond the theoretical level to study the practical applications of the system. The methods of track production proposed in Robotics may be generally divided into several methods such as trajectory control, speed control, acceleration control, and torque control.

In medical application, the Da Vinci robotic surgery system assists doctors in performing surgeries, where the 3D-HD image technology and simulated wrist surgical instruments are jointly used to form smaller and more accurate operative lacerations. The Keio University in Japan designed a five-fingered robot hand [2] equipped with capabilities for performing space missions, solving Rubik's Cube problems, classifying medicines, and even cooking every day dishes such as pancakes. However, it is rather impossible for a mechanical arm to complete certain complex manual operative tasks, such as flexible rolling, rotating, bending, and friction-sensing, because it consists of multiple parts and components, including crank, connecting rod, joint, slider, gear, belt, and bearing [3].

Renault et al. from France employed virtual technology to conduct a simulation study on an artificial hand and arm in order to realize the action of grabbing [4]. Ma Ruqi et al. from the Harbin Institute of Technology [5] applied virtual technology to the joint simulation of a mechanical arm and used PD control to effectively realize the tracking movement of the mechanical arm. There was a location sensor on the hand joint to sense the angle of the joint and a force sensor on the tendon to measure the stretch and flexion 
conditions of the fingers. This information was utilized to further control the movement of the joint and fingers in order to realize the actions of grabbing objects, etc. [6].

The clamping jaw on the mechanical arm is designed for specific tasks and has specific clamped parts. As the conception of clamp fixture, the clamping jaw is the tested institution of the axial bending moment clamp fixture [7] formulated by ASTM, and this institution uses the upper and lower brackets to complete the counterpoint of supporting structures consisting of a 1/16 inch pressure head in the center and three 1/8 inch balls on the lower circle; its test method corresponds to the pressure head pressing test coupons from above. Marin and Ferreira [8] proposed an optimized fixture design for a certain workpiece and proposed optimized fixture location and form under conditions ensuring that the workpiece would not move. According to the literature review, the continuous improvement of the mechanical arm has assisted people. Further, the mechanical arm has adopted more optimized functions compared to the traditional mechanical arms, making the fixture automation device more practical.

Research on practical robots started in the 1950s and it shifted toward practical robotic applications from theoretical academic based research, and thus revolutionized industrial development [9] in several fields. In 1956, the first industrial mechanical arm was created by Joseph F. Engelberger, known as the father of the mechanical arm. In 1962, the first industrial robot in the world was installed in the production line of the GM Automobile Company in the United States [10].

\section{Design and research method for manipulator fixture}

The major contents of this design include the design of a manipulator and three connecting rods and fixtures. The pneumatic cylinder power operation is used to drive a gear set via a belt power source pulling connecting rod and the fixture is used to achieve telescopic actions. The main advantage of the pneumatic cylinder is that it can reduce the weight of the manipulator and it can further prevent excessively fast operations by serving as a buffer during the process of stretching out and retracting. Another advantage of the pneumatic cylinder is that it can prevent excess indoor operation temperature by replacing the application of the battery valve with a traditional manipulator. The pneumatic cylinder adopts pneumatic control to drive the gear and belt pulling the connecting rod and fixture institutions. The fixture is effective for clamping industrial parts and different parts in life. It can meet working requirements by the simultaneous operation of one to three connecting rods and fixtures to complete the application and dimension design of the whole manipulator. The expanded diagram of the fixture application design of the manipulator is shown below is shown in Figure 1. 


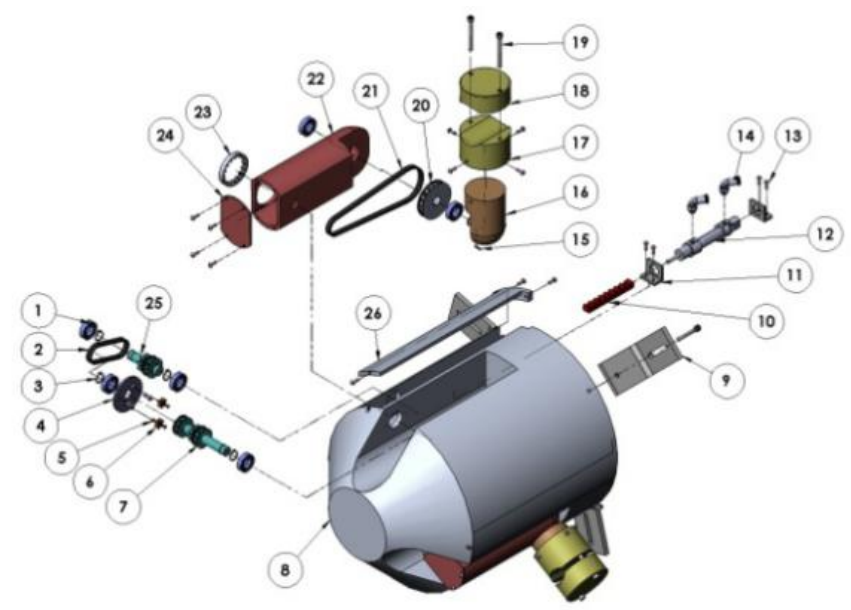

Fig. 1. The expanded diagram of the fixture application design of the manipulator.

The advantages and disadvantages of traditional robot and homemade robot Description: Generally, traditional manipulators are fixed and combined with the mechanical arm to perform a single clamping operation. In the production line or automobile industry, several mechanical arms are applied to execute the entire work flow. However, if one manipulator breaks down in the production line, the production line has to be stopped in order to replace the failed one and the repair process affects the working efficiency; moreover, small and medium enterprises usually do not have sufficient mechanical arms for replacement. Therefore, this study aims to design an optimized multi-functional manipulator that can operate like a human palm to solve these problems. It has three connecting rod functions and fixtures, and the workpiece can stretch out to operate whenever necessary. Moreover, failed clamping jaw or electro welding of the workpiece can be replaced directly, which will reduce the consumption and expenditure of mechanical arms for small and medium enterprises are shown in Table 1.

Table 1. The advantages and disadvantages of traditional and self-made hand grips.

\begin{tabular}{|l|l|l|}
\hline Project & $\begin{array}{l}\text { Traditional manipulator } \\
\text { fixtures }\end{array}$ & Homemade manipulator fixtures \\
\hline Special Requirement & Single Function & Multi-function \\
\hline $\begin{array}{l}\text { Environmental } \\
\text { Awareness }\end{array}$ & $\begin{array}{l}\text { Single-grip fixture } \\
\text { application }\end{array}$ & $\begin{array}{l}\text { Three-link function manipulator } \\
\text { fixture application }\end{array}$ \\
\hline Form Usage & $\begin{array}{l}\text { Single with robotic arm } \\
\text { execution }\end{array}$ & $\begin{array}{l}\text { Three connecting rod functions and } \\
\text { fixtures can move between } 0^{\circ} \text { to } \\
180^{\circ} \text {; mechanical arm execution }\end{array}$ \\
\hline $\begin{array}{l}\text { Workpiece } \\
\text { Replacement }\end{array}$ & $\begin{array}{l}\text { Manipulator needs to be } \\
\text { replaced entirely }\end{array}$ & $\begin{array}{l}\text { Fixture on the connecting rod of } \\
\text { manipulator can be separated and } \\
\text { changed directly. }\end{array}$ \\
\hline $\begin{array}{l}\text { Production } \\
\text { Efficiency }\end{array}$ & $\begin{array}{l}\text { Complete parts } \\
\text { independently }\end{array}$ & Can complete a number of parts \\
\hline $\begin{array}{l}\text { Production Line } \\
\text { Application }\end{array}$ & $\begin{array}{l}\text { Completed by multiple } \\
\text { mechanical arms and } \\
\text { manipulators }\end{array}$ & $\begin{array}{l}\text { A small amount of mechanical arm } \\
\text { and manipulator to complete }\end{array}$ \\
\hline $\begin{array}{l}\text { Environmental } \\
\text { Application }\end{array}$ & $\begin{array}{l}\text { Suitable for high efficiency } \\
\text { industrial field }\end{array}$ & $\begin{array}{l}\text { Suitable for Economical industrial } \\
\text { field }\end{array}$ \\
\hline
\end{tabular}




\section{Application control and stress analysis of manipulator fixture}

In this study, SolidWorks simulation was used to conduct finite element analysis and von Mises stress analysis was employed to reduce excessive driving force between gears within the manipulator to avoid the deformation of parts. Repeated analyses and modifications were carried out to obtain the optimum gear application. AISI 1045 steel was selected as the material, with properties of Young's modulus E $=204 \mathrm{GPa}$, Poisson's ratio $v=0.29$, and density $\rho=7850 \mathrm{~kg} / \mathrm{m}^{3}$ are shown in Table 2 . Model fixity offers the follower axial restraint geometry, and limits the force received by the gear contact angle on the surface of follower to apply restraint.

Table 2. Material properties.

\begin{tabular}{|l|l|}
\hline name & $\begin{array}{l}\text { AISI 1045 } \\
\text { steel }\end{array}$ \\
\hline Yield Strength & $530 \mathrm{MPa}$ \\
\hline Tensile Strength & $625 \mathrm{MPa}$ \\
\hline Elasticity Modulus & $204 \mathrm{GPa}$ \\
\hline Poisson's ratio & 0.29 \\
\hline Material density & $7.85 \mathrm{~g} / \mathrm{cm}^{3}$ \\
\hline Shear Modulus & $80 \mathrm{GPa}$ \\
\hline
\end{tabular}

Gear force analysis was performed on key parts and a fixed hinge of the gear center confined the rotation of the gear center and axle. Model loading analysis was conducted by applying a force of $47 \mathrm{~N}$ exerted by pneumatic cylinder at the top of the followeris shown Figure 2-13. The same force of $47 \mathrm{~N}$ was applied according to the rotating order of the gear and the force effect was observed to ensure sufficient stress strength for applications in part and material designs are shown in Table 3.

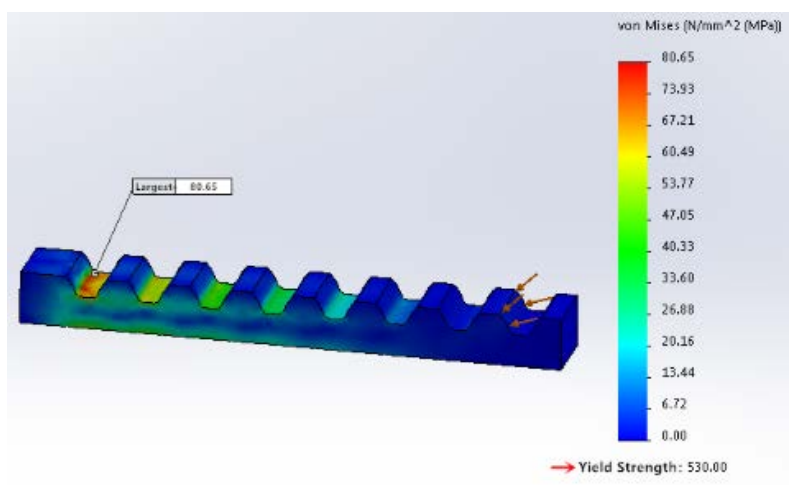

Fig. 2. Rack (8 teeth) von Mises stress diagram. 


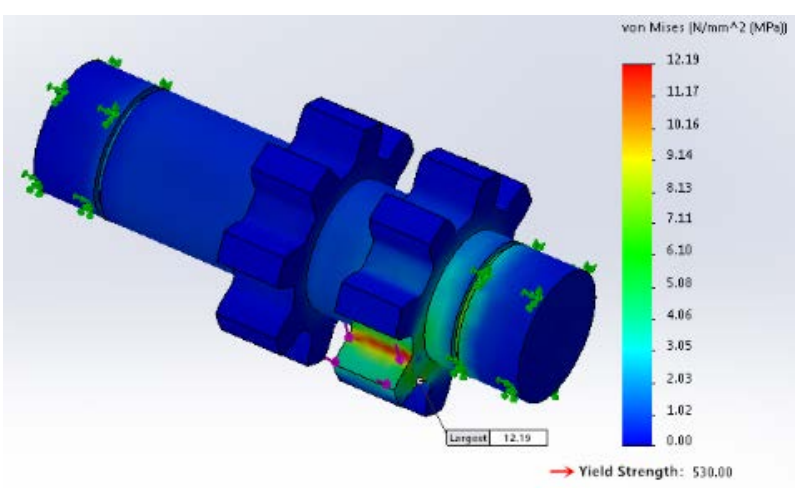

Fig. 3. Gear shaft combination -1 (two gears gear 8 teeth) von Mises stress diagram.

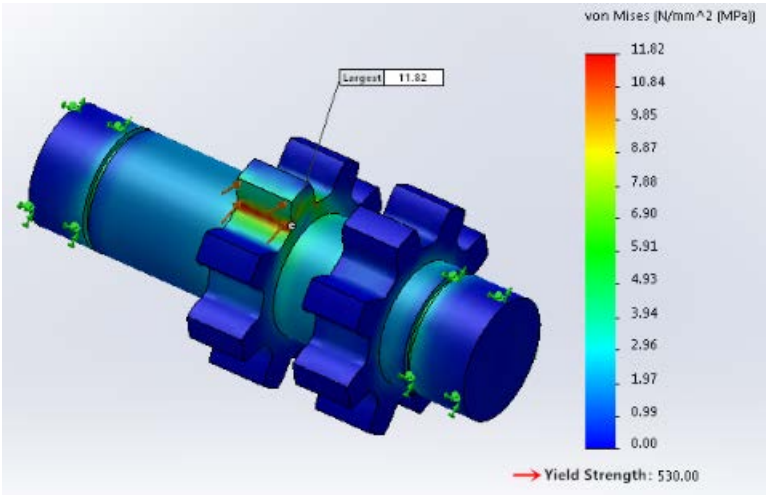

Fig. 4. Gear Shaft Combination - 2 (two gears are 8 teeth) von Mises stress diagram.

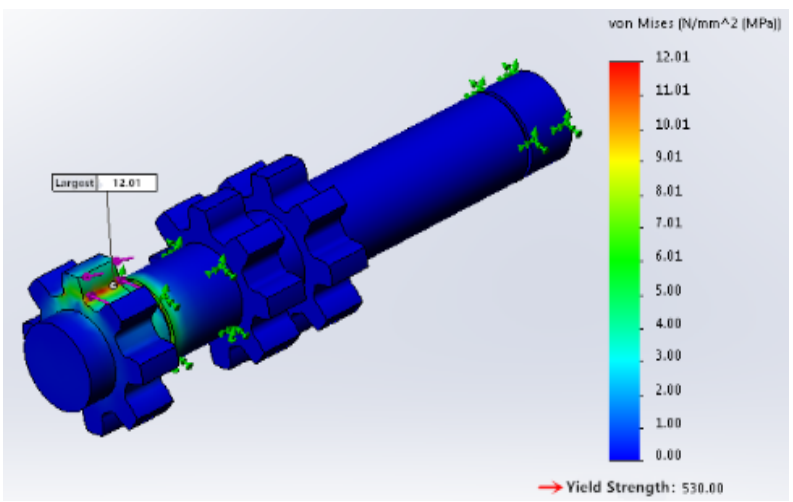

Fig. 5. Gear shaft combination -1 (three gear 8 teeth) von Mises stress diagram. 


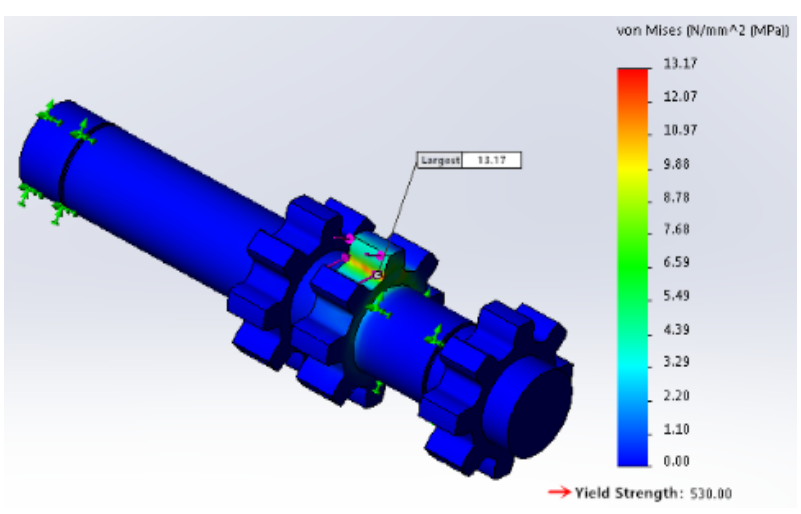

Fig. 6. Gear shaft combination -2 (three gear 8 teeth) von Mises stress diagram.

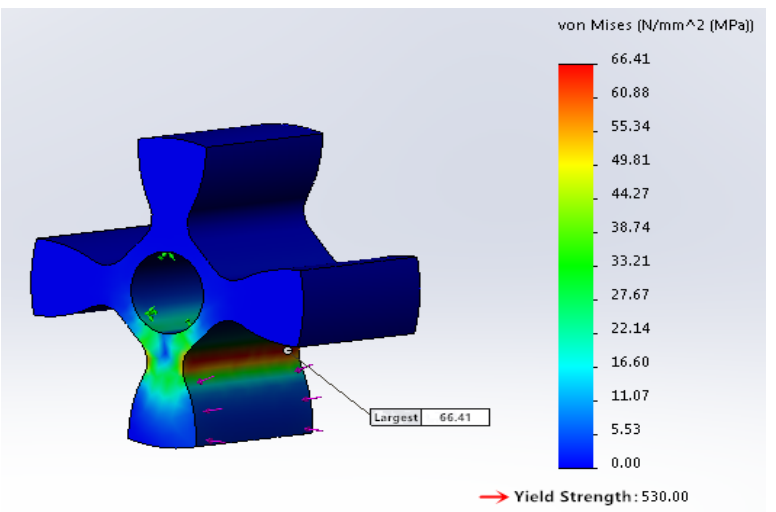

Fig. 7. Below the planet gear (gear 4 teeth) von Mises stress map.

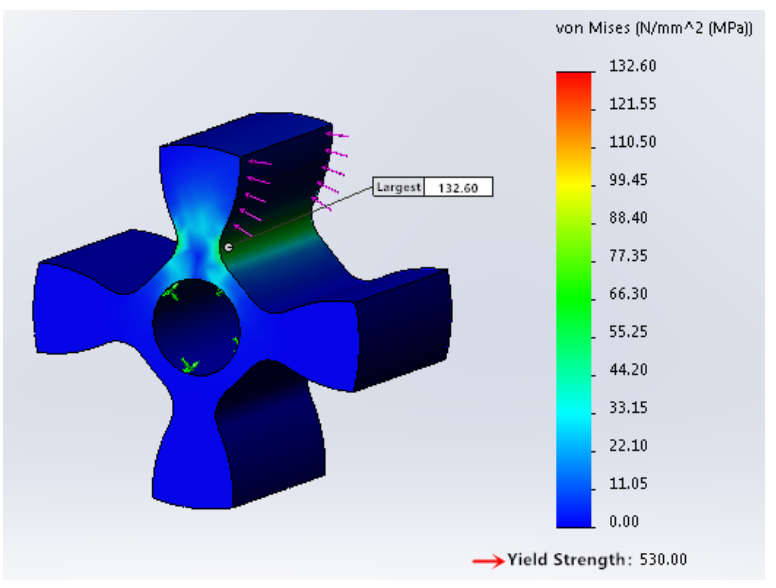

Fig. 8. Planetary gear above (gear 4 teeth) von Mises stress diagram. 


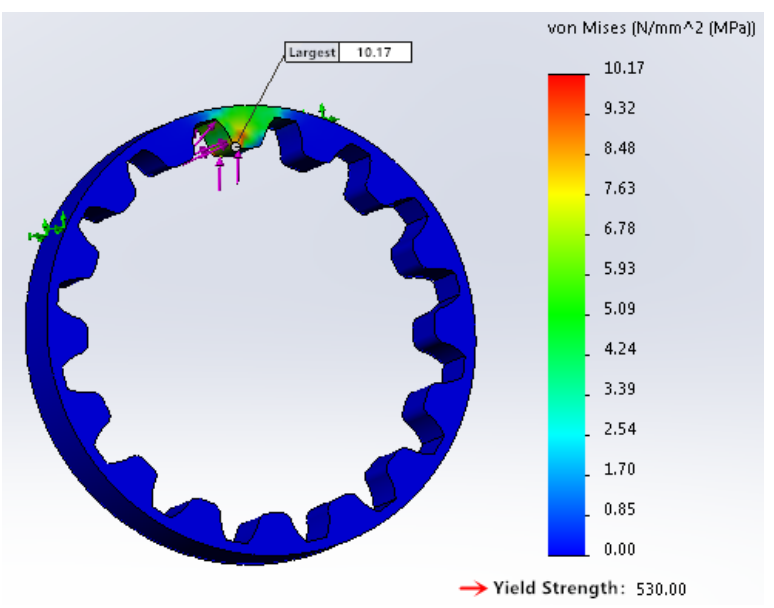

Fig. 9. Planetary gear (gear 16 teeth) von Mises stress diagram.

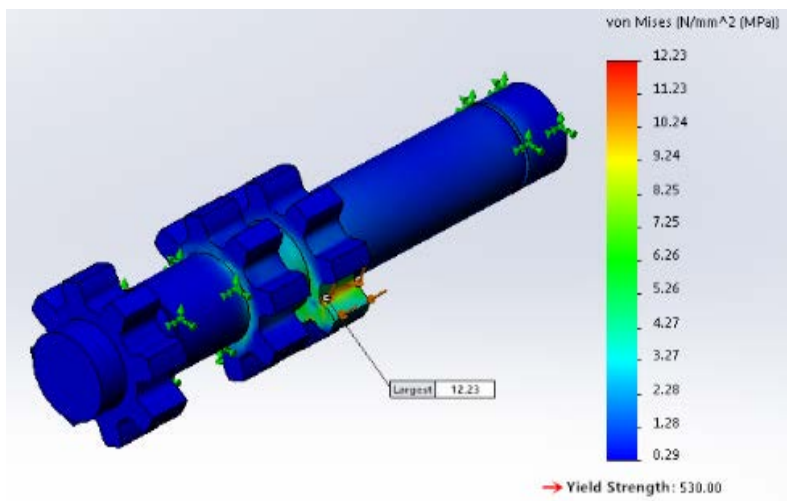

Fig. 10. Gear shaft combination -3 (three gear 8 teeth) von Mises stress diagram.

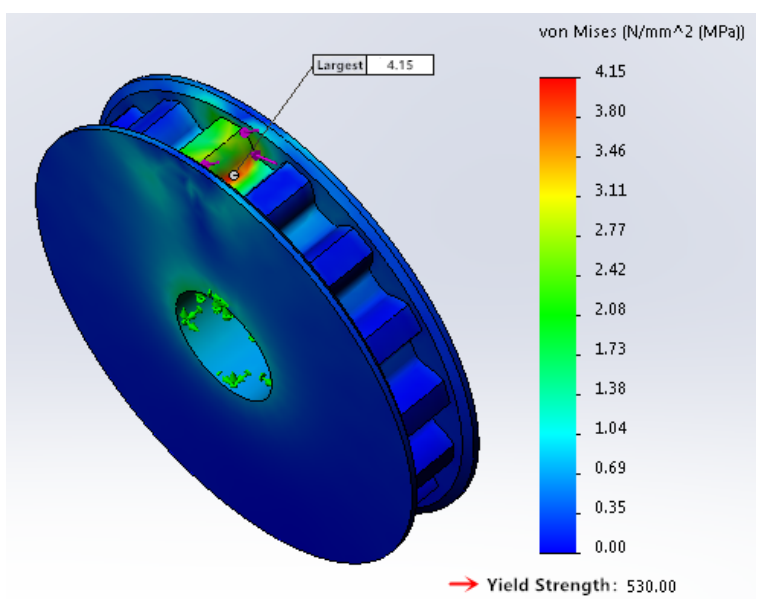

Fig. 11. Gear (16 teeth) von Mises stress diagram von Mises stress diagram. 
Table 3. von Mises stress under gear stress condition.

\begin{tabular}{|l|c|c|}
\hline \multicolumn{1}{|c|}{ Type of Gears } & Gear weight (g) & von Mises stress (MPa) \\
\hline $\begin{array}{l}\text { Gear shaft combination }-1 \\
\text { (two gears gear 8 teeth) }\end{array}$ & 19.17 & 80.65 \\
\hline $\begin{array}{l}\text { Gear shaft combination -2 } \\
\text { (two gears gear 8 teeth) }\end{array}$ & 33.63 & 12.19 \\
\hline $\begin{array}{l}\text { Gear shaft combination -1 (three } \\
\text { gear 8 teeth) }\end{array}$ & 54.81 & 11.82 \\
\hline $\begin{array}{l}\text { Gear shaft combination -2 (three } \\
\text { gear 8 teeth) }\end{array}$ & 54.81 & 13.17 \\
\hline $\begin{array}{l}\text { Below the planet gear } \\
\text { (gear 4 teeth) }\end{array}$ & 1.05 & 66.41 \\
\hline $\begin{array}{l}\text { Planetary gear above (gear 4 teeth) } \\
\text { von Mises stress diagram }\end{array}$ & 1.05 & 132.60 \\
\hline Planetary gear (gear 16 teeth) & 8.45 & 10.17 \\
\hline $\begin{array}{l}\text { Gear shaft combination -3 (three } \\
\text { gear 8 teeth) }\end{array}$ & 54.81 & 12.23 \\
\hline $\begin{array}{l}\text { Gear (16 teeth) von Mises stress } \\
\text { diagram }\end{array}$ & 49.89 & 4.15 \\
\hline
\end{tabular}

von Mises stress was applied to the manipulator fixture; planetary external gear supported the interaction of the connecting rod and fixture, and equivalent stress of this structure was calculated under a yield strength of $530 \mathrm{MPa}$ to obtain the maximum load above the fixture of $680.68 \mathrm{~N}$. Structure damage, due to excessive stress when clamping industrial accessories, was also avoided, as shown in Fig. 12.

When the load above the fixture is $680.68 \mathrm{~N}$, the maximum stress received by connecting rod head is $27 \mathrm{MPa}$. Such conditions will not exceed $530 \mathrm{MPa}$ yield strength to cause excessive deformation and damage, as shown in Fig. 13.

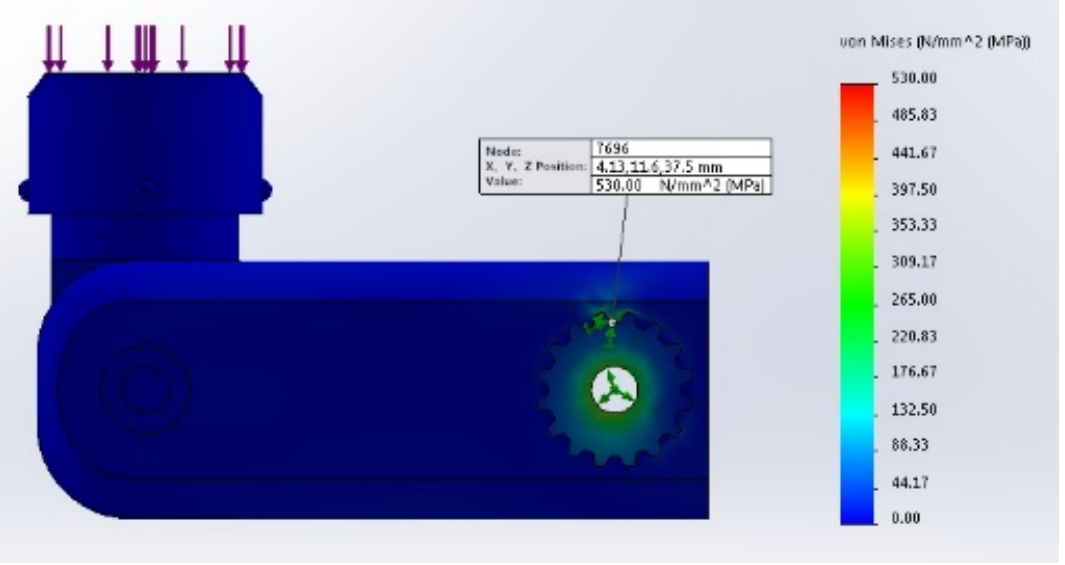

Fig. 12. Drawing of maximum load of planetary external gear under yield strength. 


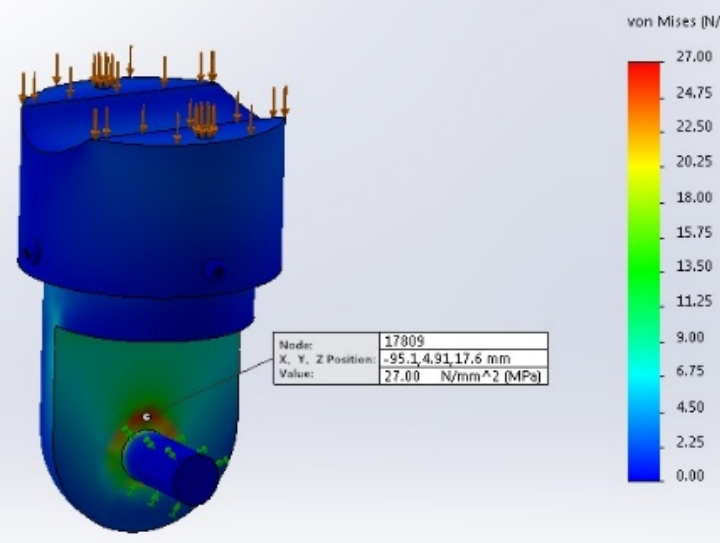

Fig. 13. Drawing of von Mises stress of fixture and connecting rod head.

The design of the manipulator fixture in this study emphasized a flexibility and action pattern that is similar to a human palm, and the simplified institution design and freedom in the degree of motion control made it possible to perform the required actions is shown in Fig. 14.

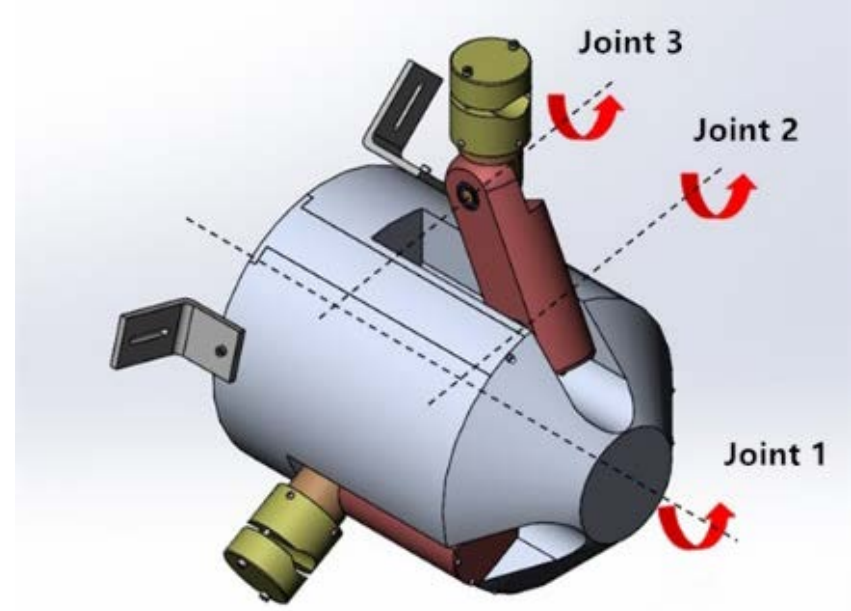

Fig. 14. Robot fixture design freedom of use map.

Manipulator fixture application joint (1) can be fixed with the mechanical arm and rotated from $0^{\circ}$ to $360^{\circ}$; then, internal pneumatic cylinder of the manipulator drives the gear to rotate the internal planetary gear set of joint (2) by rotating the connecting rod from $0^{\circ}$ to $180^{\circ}$; finally, joint (2) connecting rod is transmitted to joint (3) for uniform rotational degree of freedom from $0^{\circ}$ to $180^{\circ}$ are shown in Table 4 .

Table 4. Robotic fixture application design freedom table.

\begin{tabular}{|c|c|}
\hline Joint 1 & $0^{\circ}$ to $360^{\circ}$ \\
\hline Joint 2 & $0^{\circ}$ to $180^{\circ}$ \\
\hline Joint 3 & $0^{\circ}$ to $180^{\circ}$ \\
\hline
\end{tabular}


Firstly, section A is the main power source to match racks for the distance control pushed out by the pneumatic cylinder. The pushed distance rack will enable the first gear of the two gear sets to rotate reversely, and the coaxial second gear will rotate in the reverse direction to pull the belt and rotate the first gear of another three-gear set; then, the pulled first gear and second gear will rotate coaxially to drive the whole planetary gear set in section B; the planetary external gear has to be welded and fixed with the connecting rod to rotate the connecting rod from $0^{\circ}$ to $180^{\circ}$ due the rotation of the pinion. Finally, in section $\mathrm{D}$, the third gear of three-gear set rotates coaxially to pull the belt and combines the connecting rod head and fixture to jointly rotate from $0^{\circ}$ to $180^{\circ}$ as shown in Fig. 15-16.

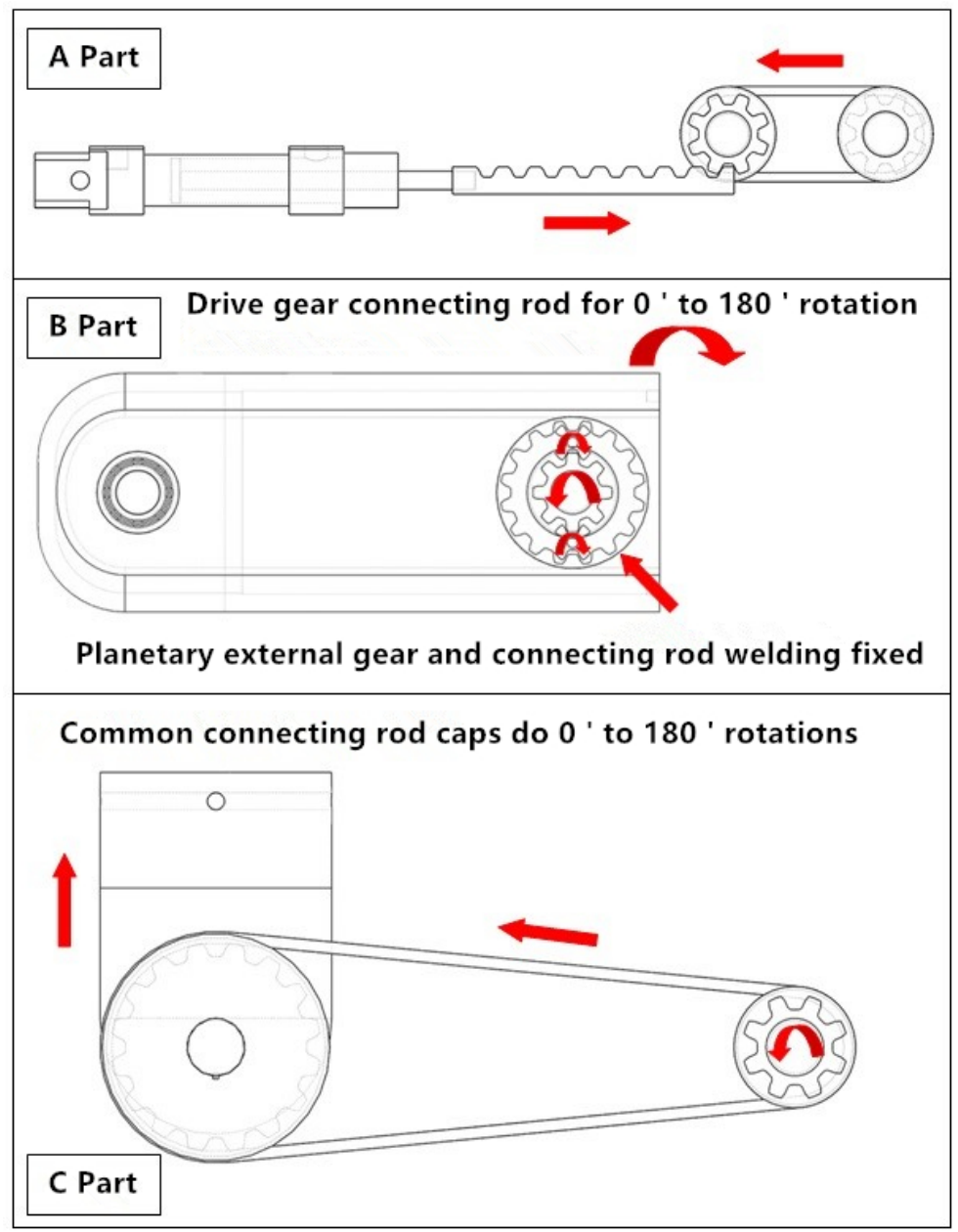

Fig. 15. Manipulator application motion control simulation. 


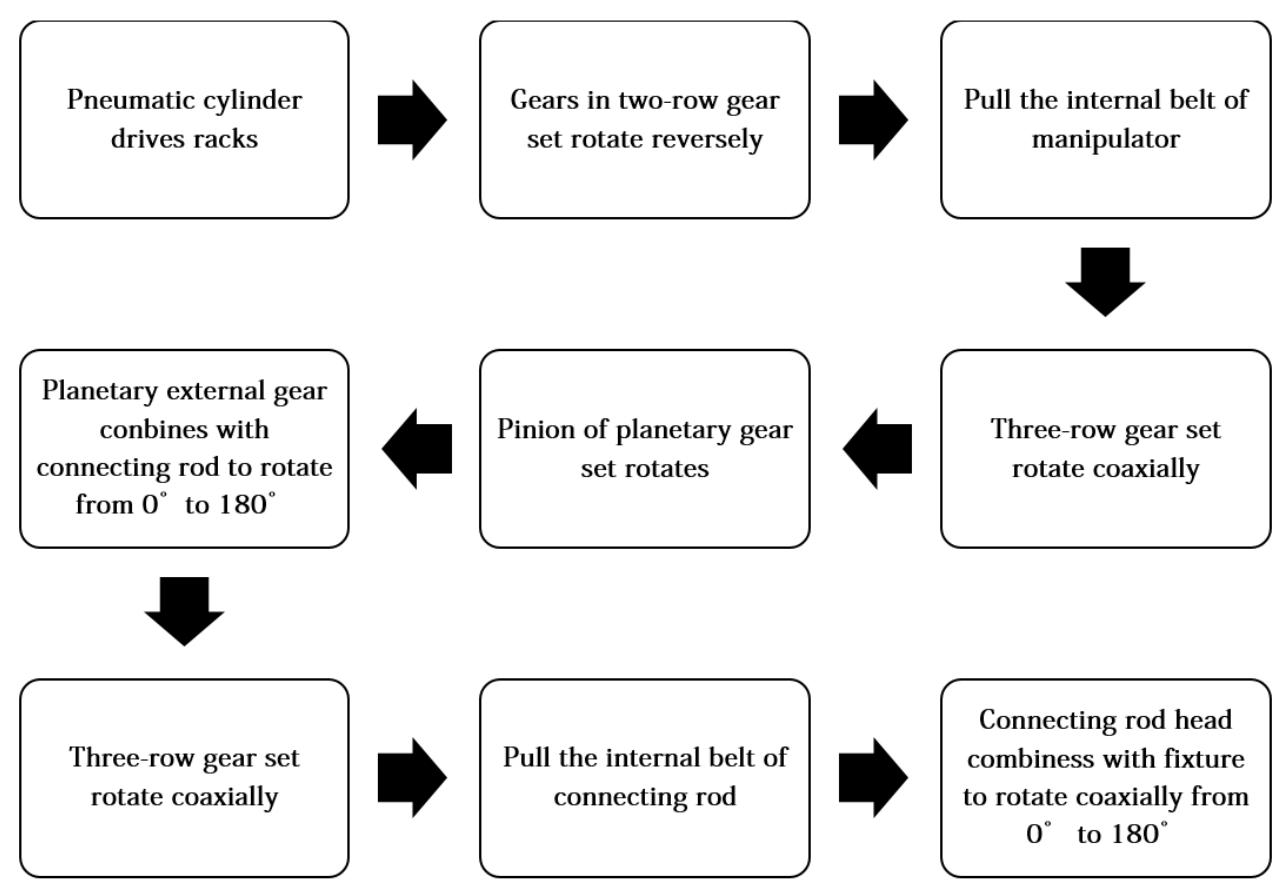

Fig. 16. Flow Diagram of Transmission Operation Mode.

\section{Conclusions}

In this study, the design of the whole process refers to the industrial mechanical arm for coordinating the design size of the manipulator, the number of gear teeth in the overall application and gear appearance design that conforms to the overall application of the manipulator in consideration of movement, and the ideal angle of the connecting rod and fixture operation that has to be achieved; the transmission of every gear must match with one-piece to complete the task. The conclusions of this study are as follows:

1. The concept of a simulated human palm is used to design the application of a manipulator fixture; sizes of all parts are designed as stipulated in the main body of the manipulator; three connecting rods are applied to functions for achieving stretching out and drawing back, and they jointly rotate with the fixture; a fixture is used to clamp three kinds of industrial accessories or household appliances.

2. In response to the gear institution stress analysis, design of the gear, and selection of materials, the stress effect caused by the application of $47 \mathrm{~N}$ force exerted by a pneumatic cylinder will be calculated to obtain sufficient stress strength for applications. Then, the maximum limit of stress for every gear institution is calculated and the results show that the maximum limit is $308.85 \mathrm{~N}$ in order to avoid the deformation and damage of gears due to excessive stress limits. Finally, the maximum load above the fixture is $680.68 \mathrm{~N}$, and the connecting rod head will not be damaged when the stress is less than $27 \mathrm{MPa}$.

3. After setting the electrical control circuit, the motion control pattern provides signals to the air source of the electromagnetic valve with five connecters and two positions. The buffer enables the pneumatic cylinder to combine the actions of stretching out and drawing back to operate the whole transmission system architecture. Finally, the connecting rod performs the action of stretching out and drawing back to achieve 
rotations and applications between $0^{\circ}$ to $180^{\circ}$ with the fixture.

4. In compliance with users' demands, the application of the manipulator fixture to motion simulation will be applicable for one to three connecting rods and fixtures operations. One connecting rod and fixture can achieve separate applications of stretching out and drawing back; two connecting rods and fixtures can achieve doubleapplications of stretching out and drawing back; finally, three connecting rods and fixtures can be used if the users have extensive demands, and the fixtures can be adopted to clamp effective industrial equipment applications and meanwhile achieve improved production speed.

\section{References}

1. R.J. Full and D.E. Koditschek, Templates and Anchors: Neuromechanical Hypotheses of Legged Locomotion on Land, Journal of Experimental Biology, 1999. 202(23): pp. 3325-3332

2. I. Yamano and T. Maeno, Five-finger Robot Hand using Ultrasonic Motors and Elastic Elements, in Proceeding of the 2005 IEEE International Conference on Robotics and Automation, pp. 2673-2678, 2005

3. M. Saitohand and K. Furuta, Generalized minimum variance control of slidercrank mechanism, in SICE Annual Conference, pp. 2205-2209, 2007

4. M. Renault and F.B. Ouezdou, Dynamic simulation of hand-forearm system, IEEE International Workshop on Robot and Human Interactive Communication, pp. 2025,2001

5. R.Q. Ma, S.H. Hao, W.F. Zheng, M. H. Hao, B.Y. Song, Research on coordinated simulation of robot arm based on MATLAB and ADAMS. Machinery Design \& Manufacture, pp. 93-95, 2010

6. P. Michelman, Precision Object Manipulation with a Multi-fingered Robot Hand, IEEE Transactions on Robotics and Automation, Vol. 14, No. 1, pp. 105-113, 1998

7. ASTM, Standard test method for biaxial flexure strength (modulus of rupture) of ceramic substrates, ASTM F394-78. American Society for Testing and Materials, Philadelphia, PA. 1996

8. R.A. Marinand and P. M.Ferreira, Optimal placement of fixture clamps: Minimizing the maximum clamping forces, Journal of Manufacturing Science and Engineering, Transactions of the ASME, Vol. 124, No. 3, pp. 686-694, 2002

9. J.Q. Gan, E. Oyama, E. M. Rosales, H. Hu, A Complete Analytical Solution to the Inverse Kinematics of the Pioneer2 Robotic Arm, J. of Robotica, vol. 23, pp. 123129,2005

10. H. P. Huang, Y.T. Chen, R.J. Wang, M.K. Chi, Development of the multi-axis control platform for robot arm, IEEE, Proceedings of Annual Conference, pp. 2326-2331, 2010 